\section{VASECTOMY IN A RHESUS MONKEY MACACA MULATTA}

\section{Vandana Sangwan ${ }^{1, \star}$ and Nishtha Pathak ${ }^{1}$}

${ }^{1}$ Veterinary Doctor, People for animals, Chandigarh

* Present Address: Research Fellow, Department of Veterinary Surgery and Radiology, GADVASU, Ludhiana, Punjab 141004, India Email: * drvandanasangwan@rediffmail.com

Increasing population of certain species of wild animals maintained in captivity necessitates their sterilization to effectively control their numbers. Vasectomy is the surgical method that makes the animal incapable to produce (sterile) but maintains its normal sexual behaviour. There are scanty reports on operative technique for vasectomy in monkeys (Mostafa et al., 2004). The postoperative surgical wound management in wild animals, especially monkeys, is still a challenge. The present communication describes the anaesthesia, operative technique and postoperative care in a monkey operated for vasectomy.

A young male Rhesus Monkey (Macaca mulatta) weighing about $2 \mathrm{~kg}$ was brought to the clinic by the Forest Department, Chandigarh. The animal was caught from a residential colony where it was supposedly creating nuisance. The forest department wanted the animal to be sterilized and then to be left in a forest. The animal was kept in a cage for about one week to assess the health and behaviour and was found clinically fit for surgery. The animal was kept off-feed and offwater for 12 and $3 \mathrm{hr}$, respectively, before the operation. Diazepam $1.0 \mathrm{mg} / \mathrm{kg}$ was injected, intramuscularly, with a disposable syringe in the cage itself, by holding the monkey's tail. The animal was deeply sedated in about 10 minutes. It was taken out of the cage and brought to the operation theatre. The scrotum and surrounding area was prepared aseptically for surgery. Ketamine $8 \mathrm{mg} / \mathrm{kg}$ (total dose $16 \mathrm{mg}$ ) was injected, intravenously, for induction of anesthesia. The anesthesia was maintained with ketamine alone as and when required, with the half dose rate intravenously.

A horizontal skin incision was given slightly on the anterior one side of the scrotum. Tunica dartus and tunica vaginalis were properly incised and the testicle was taken out. Following the epididymis the spermatic cord was traced and a glistening white structure, the vas deferens was identified. The vas deferens was ligated at two places about $2 \mathrm{~cm}$ apart using $2-0$ Vicryl and a piece of the duct (about $2-3 \mathrm{~mm}$ ) was removed to prevent recanalization. The testicle was placed back in the scrotum and subcutaneous sutures using 2-0 vicryl were applied to appose the skin edges. No external skin sutures were applied. The same procedure was repeated for the other side of the duct. The total time taken including induction of anesthesia was 30 minutes. No fluid therapy was given during or after the operation. The animal was given ampicillin $250 \mathrm{mg}$ and analgin $1 \mathrm{ml}$, intramuscularly, in the unconscious state. Topical dressing of the wound was done with betadine. Recovery from anaesthesia was observed within 15-20 minutes of the completion of the operation. The animal was transferred back into the cage. The animal started taking liquid diet within twelve hours of the operation. Later on, the animal did not allow administration of parenteral medicine, nor took it orally. Only povidone iodine solution was sprayed with syringe twice daily for three consecutive days. The animal tried to see the surgical wound on the first day but did not mutilate it. The surgical wound healed uneventfully without any complications within seven days.

In adult and heavy breeds of monkeys the testicles and spermatic cord are usually well-developed and vasectomy can be performed as described in other animals, i.e. by approaching the vas deferens from lateral side of the spermatic cord (Rubin \& Maplesdon, 1977; Mostafa et al., 2004) but in the present study the spermatic cord could not be felt from the skin so the testicle was taken out to trace the vas deferens. In this case study, the surgical wound healed uneventfully and buried subcuticular sutures were found suitable for skin closure (Sangwan et al., 2003) for vasectomy in monkey.

\section{REFERENCES}

Mostafa, M.B., S.G. Okech \& J.A. Azikuri (2004). Vasectomy in a monkey (Erythocybus patas). Indian Journal of Veterinary Surgery 25(1): 65. Rubin, L.D. \& D.C. Maplesdon (1977). A technique for vasectomy in dogs. Veterinary Medicine: Small Animal Clinicians 72: 579.

Sangwan, V., A.P. Singh, Geeta \& A. Kumar (2003). Comparative clinical studies on closure of skin incision with tissue adhesive (Iso amyl-2 cyanoacrylate) or subcuticular sutures in dogs. Haryana Veterinarians 42: $45-47$.

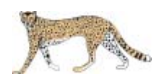

Manuscript 1637; (C) ZOO; Date of publication 24 January 2007 Received 04 September 2006; Revised received 04 December 2006; Finally accepted 10 January 2007 